\title{
Boosting Indicator-based Selection Operators for Evolutionary Multiobjective Optimization Algorithms
}

\author{
Dung H. Phan \\ Department of Computer Science \\ University of Massachusetts, Boston \\ Boston, MA 02125 \\ phdung@cs.umb.edu
}

\author{
Junichi Suzuki \\ Department of Computer Science \\ University of Massachusetts, Boston \\ Boston, MA 02125 \\ jxs@cs.umb.edu
}

\begin{abstract}
Various evolutionary multiobjective optimization algorithms (EMOAs) have adopted indicator-based selection operators that augment or replace dominance ranking with quality indicators. A quality indicator measures the goodness of each solution candidate. Many quality indicators have been proposed with the intention to capture different preferences in optimization. Therefore, indicator-based selection operators tend to have biased selection pressures that evolve solution candidates toward particular regions in the objective space. An open question is whether a set of existing indicator-based selection operators can create a single operator that outperforms those existing ones. In order to address this question, this paper proposes and evaluates a method to aggregate (or boost) existing indicator-based selection operators. Experimental results show that a boosted selection operator outperforms exiting ones in optimality, diversity and convergence velocity. It also exhibits robustness against different characteristics in different optimization problems and yields stable performance to solve them.
\end{abstract}

Keywords-Evolutionary multiobjective optimization algorithms, Quality indicators, Boosting

\section{INTRODUCTION}

This paper studies a new selection operator for evolutionary algorithms to solve multiobjective optimization problems (MOPs). In general, an MOP is described as follows.

$$
\left.\begin{array}{r}
\operatorname{minimize} F(\vec{x})=\left[f_{1}(\vec{x}), f_{2}(\vec{x}), \cdots, f_{n}(\vec{x})\right]^{T} \in \mathcal{O} \\
\text { subject to } \vec{x}=\left[x_{1}, x_{2}, \cdots, x_{m}\right]^{T} \in \mathcal{S}
\end{array}\right\}
$$

$\mathcal{S}$ denotes the decision variable space. $\vec{x} \in \mathcal{S}$ denotes a solution candidate that consists of $m$ decision variables. It is called an individual in evolutionary multiobjective optimization algorithms (EMOAs). $F$ consists of $n$ real-value objective functions, which produce the objective values of $\vec{x}$ in the objective space $\mathcal{O}$. The goal of an EMOA is to find an individual(s) that minimize(s) objective values.

In MOPs, there rarely exists a single solution that is optimum with respect to all objectives because objective functions conflict with each other. Thus, EMOAs seek the optimal trade-off individuals, or Pareto-optimal individuals, by considering the trade-offs among conflicting objectives. The notion of dominance plays an important role to seek Pareto optimality [1]. An individual $\vec{x} \in \mathcal{S}$ is said to dominate another individual $\vec{y} \in \mathcal{S}$ iif $f_{i}(\vec{x}) \leq f_{i}(\vec{y}) \forall i=1, \cdots, n$ and $f_{i}(\vec{x})<f_{i}(\vec{y}) \exists i=1, \cdots, n$. EMOAs often rank individuals based on the dominance relationships among them and exploit their ranks in selection operators [1]. This process is called dominance ranking.

A research trend in the design space of EMOAs is to adopt indicator-based selection operators that augment or replace dominance ranking with quality indicators [2]. A quality indicator measures the goodness of each individual. Recent studies (e.g., [3]) show that indicator-based EMOAs outperform traditional EMOAs that use dominance ranking.

Many quality indicators have been proposed with the intention to capture different preferences in optimization [4][7]. Therefore, indicator-based selection operators tend to have biased selection pressures that evolve individuals toward particular regions in the objective space. For example, the hypervolume indicator favors balanced individuals that equally balance the trade-offs among all objectives, while the weighted hypervolume indicator favors extreme individuals that yield superior performance only in a limited number of objectives [4]. An open question in this context is whether a set of existing indicator-based selection operators can create a single operator that outperforms those existing ones.

In order to address this question, this paper proposes and evaluates a method to aggregate (or boost) existing indicator-based selection operators ${ }^{1}$. This boosting process is carried out with a training problem in which Paretooptimal solutions are known. Experimental results show that a boosted selection operator outperforms exiting ones in optimality, diversity and convergence velocity. The proposed boosting process can work with a simple training problem, and the boosted operator can effectively solve harder problems. The boosted operator also exhibits robustness against different characteristics in different problems and yields stable performance to solve them.

\footnotetext{
${ }^{1}$ In this paper, a selection operator means a parent selection operator, which chooses individuals from the population to reproduce offspring.
} 


\section{RELATED WORK}

To the best of the authors' knowledge, this work is the first attempt to boost selection operators in evolutionary algorithms (EAs) although boosting has been integrated with EAs in several other ways.

For example, boosting has been integrated with genetic algorithms (GAs) to solve classification problems [8]-[10]. The Boosting Genetic Algorithm integrates boosting with a GA to discover classification rules [8]. A GA is used as a base classifier in which each individual represents a classification rule. A boosting algorithm aggregates multiple base classifiers to build a more accurate classifier than them.

Liu et al. integrate boosting with a GA for feature selection [9]. The aim of feature selection is to identify the features that strongly contribute to classification accuracy and eliminate the other features. A GA evolves a set of individuals, each of which encodes a feature selection candidate, and seeks the optimal feature selection that minimizes classification error. The fitness of an individual is computed as the mean classification error of boosted classifiers, each of which is associated with a feature. A set of base classifiers are assigned to each feature, and a boosting algorithm constructs a boosted classifier from them.

Yalabik et al. propose a GA to seek the optimal permutation of base classifiers as a boosted classifier [10]. Each individual in the GA represents a set of base classifiers. The fitness of an individual is computed as the classification error of a boosted classifier aggregating the base classifiers that the individual represents.

GPBoost [11] and its variants (e.g., [12]) integrate boosting with genetic programming (GP) to solve regression problems. A GP algorithm is used as a base learner (i.e., regression solver), and a boosting algorithm aggregates multiple base learners.

\section{QUALITY INDICATORS}

This section describes 15 representative quality indicators that the proposed boosting method uses.

\section{A. Hypervolume Indicator $\left(I_{H}\right)$}

$I_{H}$ measures the volume of a hypercube that an individual dominates in the objective space [13]. The hypercube is formed with the individual and the reference point representing the highest (or worst) possible objective values $\vec{r}=\left(r_{1}, r_{2}, . ., r_{n}\right)$ where $n$ denotes the number of objectives. $I_{H}$ of an individual $\vec{x}$ is calculated as follows where $f_{i}(\vec{x})$ denotes the $i^{\text {th }}$ objective function value of $\vec{x}$.

$$
I_{H}(\vec{x})=\prod_{i=1}^{n}\left|r_{i}-f_{i}(\vec{x})\right|
$$

$I_{H}$ is intended to favor balanced individuals in objective space rather than extreme ones [13].

\section{B. Weighted Hypervolume Indicator $\left(I_{W 1}\right.$ to $\left.I_{W 9}\right)$}

$I_{W}$ is an extension to $I_{H}$ in that $I_{W}$ places different weights on different regions in the objective space while $I_{H}$ places the uniform weight on all regions [4]. $I_{W}$ of an individual $\vec{x}=\left(x_{1}, x_{2}, \ldots, x_{n}\right)$ is computed as follows.

$$
\begin{aligned}
& I_{W}(\vec{x})= \int_{\left(x_{1}, x_{2}, \ldots, x_{n}\right)}^{\left(r_{1}, r_{2}, \ldots, r_{n}\right)} w(\vec{a}) d z \\
& \text { where } w(\vec{a})=\frac{\sum_{i=1}^{n} e^{k_{i}\left(r_{i}-a_{i}\right)}}{\sum_{i=1}^{n} e^{k_{i}}}
\end{aligned}
$$

$w(\vec{a})$ denotes the weight of a point $\vec{a}=\left(a_{1}, a_{2}, \ldots, a_{n}\right)$ in the objective space. It is calculated by applying a weight distribution $\vec{k}=\left(k_{1}, k_{2}, . ., k_{n}\right) . k_{i}$ is the weight assigned to the $i^{\text {th }}$ objective. Given a greater $k_{i}$ value, $I_{W}$ favors extreme individuals that are closer to the $f_{i}$ axis in the objective space. Note that $I_{W}$ is equal to $I_{H}$ when $\vec{k}=(0,0, . ., 0)$.

As shown in Table I, this paper considers nine variants of $I_{W}$ ( $I_{W 1}$ to $\left.I_{W 9}\right)$ based on nine different combinations of $k_{1}$ and $k_{2}$ values. Note that this papers uses a training problem whose objective space is two dimensional.

Table I: 9 Variants of the Weighted Hypervolume Indicator

\begin{tabular}{|c|c|c||c|c|c|}
\hline$I_{W}$ variants & $k_{1}$ & $k_{2}$ & $I_{W}$ variants & $k_{1}$ & $k_{2}$ \\
\hline \hline$I_{W 1}$ & 10 & 10 & $I_{W 6}$ & 0 & 20 \\
$I_{W 2}$ & 10 & 0 & $I_{W 7}$ & 30 & 30 \\
$I_{W 3}$ & 0 & 10 & $I_{W 8}$ & 30 & 0 \\
$I_{W 4}$ & 20 & 20 & $I_{W 9}$ & 0 & 30 \\
$I_{W 5}$ & 20 & 0 & & & \\
\hline
\end{tabular}

\section{HypE Indicator $\left(I_{\text {Hyp }}\right)$}

$I_{H y p E}$ is also an extension to $I_{H}$. This indicator places different weights on different portions in the hypervolume that an individual dominates. The hypervolume is divided into multiple portions based on how many other individuals dominate it as well. $I_{\text {HypE }}$ of $\vec{x}$ is computed as follows [5].

$$
I_{\text {HypE }}(\vec{x})=\sum_{i=1}^{\mu} \frac{1}{i} H_{i}(\vec{x})
$$

$\mu$ denotes the population size (i.e., the number of individuals in the population). $H_{i}(a)$ denotes the hypervolume that is dominated by $\vec{x}$ and other $(i-1)$ individuals in the population. $H_{1}$ is the hypervolume that $\vec{x}$ dominates exclusively. The highest weight of 1 is given to $H_{1} \cdot H_{2}$ is the hypervolume that $\vec{x}$ and another individual dominate. The second highest weight of $\frac{1}{2}$ is given to $H_{2}$. The lowest weight of $\frac{1}{\mu}$ is given to $H_{\mu}$, which all individuals in the population dominate.

\section{Binary $\varepsilon+$ Indicator $\left(I_{\varepsilon+1}\right.$ and $\left.I_{\varepsilon+2}\right)$}

$I_{\varepsilon}$ takes two individuals ( $\vec{x}$ and $\vec{y}$ ) and measures the distance between them on a per-objective basis. It is computed as follows [6]. 


$$
I_{\epsilon+}(\vec{x}, \vec{y})=\max _{i \in\{1, . ., n\}}\left(f_{i}(\vec{x})-f_{i}(\vec{y})\right)
$$

This paper considers two methods to evaluate the quality of an individual $(\vec{x})$ against the other individuals in the population $P$. The first method is to sum up binary indicator values.

$$
I_{\epsilon+1}(\vec{x})=\sum_{\vec{y} \in P \backslash\{\vec{x}\}} I_{\epsilon+}(\vec{y}, \vec{x})
$$

The second method amplifies the influence of dominating individuals over dominated one.

$$
I_{\epsilon+2}(\vec{x})=\sum_{\vec{y} \in P \backslash\{\vec{x}\}}-e^{-I_{\epsilon+}(\vec{y}, \vec{x}) / l}
$$

$l$ is a scaling coefficient. $l=0.05$ in this paper, which is a recommended value in [6].

\section{E. Binary Hypervolume Indicator $\left(I_{H D 1}\right.$ and $\left.I_{H D 2}\right)$}

$I_{H D}$ takes two individuals $(\vec{x}$ and $\vec{y})$ and measures the hypervolume dominated by $\vec{x}$ but not by $\vec{y}[6]$.

$$
I_{H D}(\vec{x}, \vec{y})= \begin{cases}H(\vec{x})-H(\vec{y}) & \text { if } \vec{x} \text { dominates } \vec{y} \\ H(\vec{x})-H(\vec{x}) \cap H(\vec{y}) & \text { otherwise }\end{cases}
$$

$H(\vec{x})$ denotes the hypervolume that $\vec{x}$ dominates.

Similar to $I_{\epsilon+1}$ and $I_{\epsilon+2}$, this paper considers two variants, $I_{H D 1}$ and $I_{H D 2}$, to evaluate the quality of an individual $(\vec{x})$ against the other individuals in the population. $I_{H D 1}(\vec{x})$ and $I_{H D 2}(\vec{y})$ are computed by replacing $I_{\epsilon+}(\vec{y}, \vec{x})$ with $I_{H D}(\vec{x}, \vec{y})$ in Equations 6 and 7, respectively.

\section{Boosting Selection Operators}

Algorithm 1 shows the proposed boosting process, which employs the AdaBoost algorithm [14]. It takes $M$ indicatorbased selection operators $S$ and aggregates top $T$ operators $S^{*}(T \leq M)$. This paper uses 15 tournament selection operators that use 15 indicators described in Section III $(M=15) . T$ aggregated operators have their weights: $W^{*}=\left\{\alpha_{1}, \alpha_{2}, \ldots, \alpha_{T}\right\}$.

The proposed boosting process is carried out through an offline training with a multiobjective optimization problem in which Pareto-optimal solutions are known. This training problem is used to generate $N$ training populations, $\left\{p_{1}, p_{2}, . ., p_{N}\right\}$, each of which contains $\mu$ individuals (Line 2). Of the $\mu$ individuals, $N_{p}$ individuals are Paretooptimal and $\mu-N_{p}$ individuals are randomly generated. Those $N_{p}$ Pareto-optimal individuals are selected from a training problem so that they are equally distributed on the Pareto-optimal front. Each training population has a weight $w_{i}(1 \leq i \leq N)$. Its initial value is $1 / N$ (Line 3 ).

The proposed boosting process iteratively executes a loop (Line 4 to 15) $T$ times and selects one operator in each iteration. (It selects $T$ operators through $T$ iterations.) In each iteration, each of $M$ operators selects an individual $N_{p}$ times (i.e., $N_{p}$ individuals in total) on each training population (Line 5). The operator's individual selection is considered successful if it selects $N_{p} \times \theta$ or more Paretooptimal individuals $(\theta<1)$. Given this condition, the selection error of each operator is calculated as shown in Line 7. The error is weighted with each training population's weight $w_{i}(1 \leq i \leq N)$. Then, the proposed boosting process chooses the operator $s_{t}^{*}$ that has the lowest selection error (Lines 8 and 9) and computes the operator's weight (Lines 10,11 and 12). A lower selection error contributes to a higher weight.

Finally, each training population's weight is adjusted as shown in Lines 13 and 14. The weight decreases if $s_{t}^{*}$ 's individual selection is successful; otherwise, it increases. This way, in subsequent loop iterations, the proposed boosting process focuses on the training populations on which individual selection failed and favors the operators that perform successful individual selection on those populations.

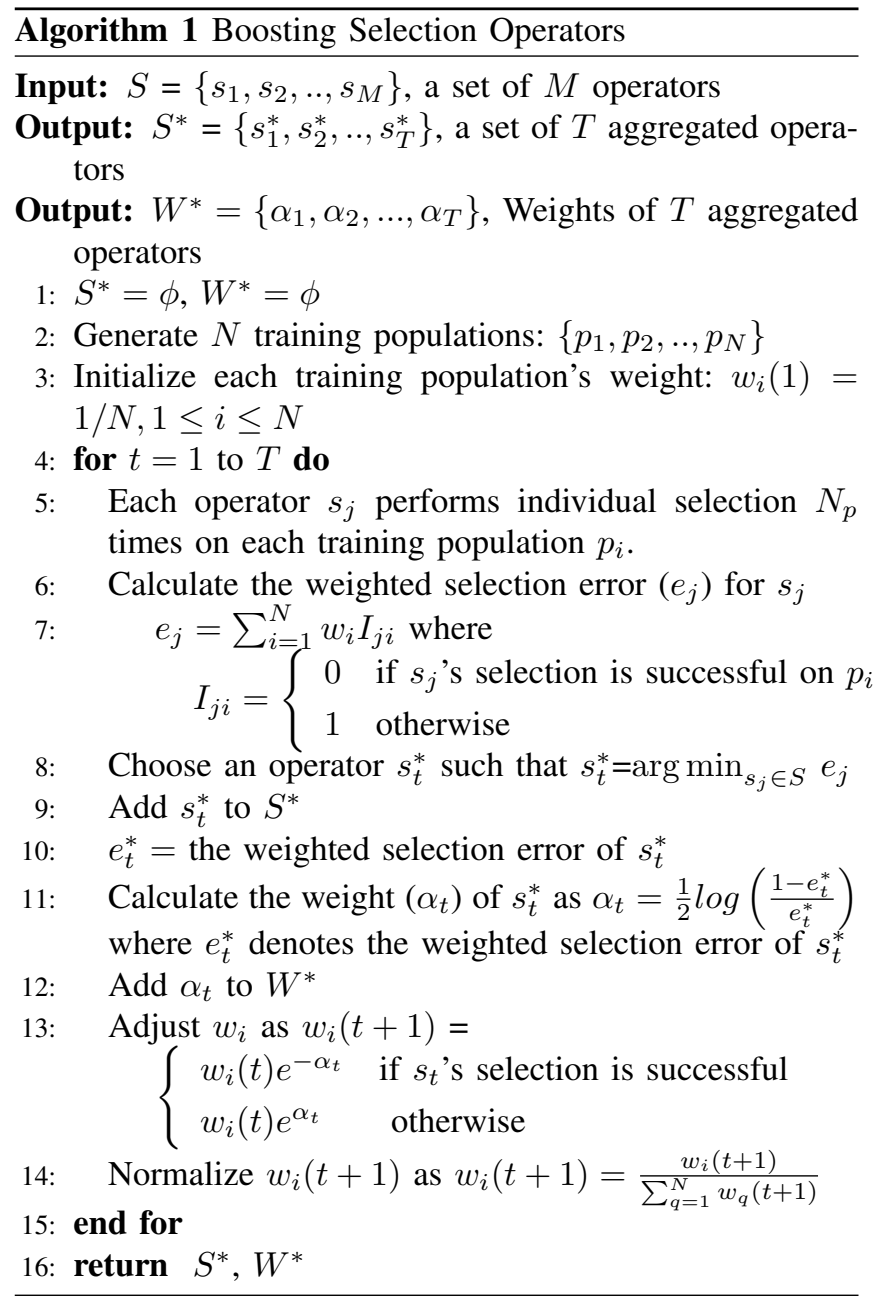




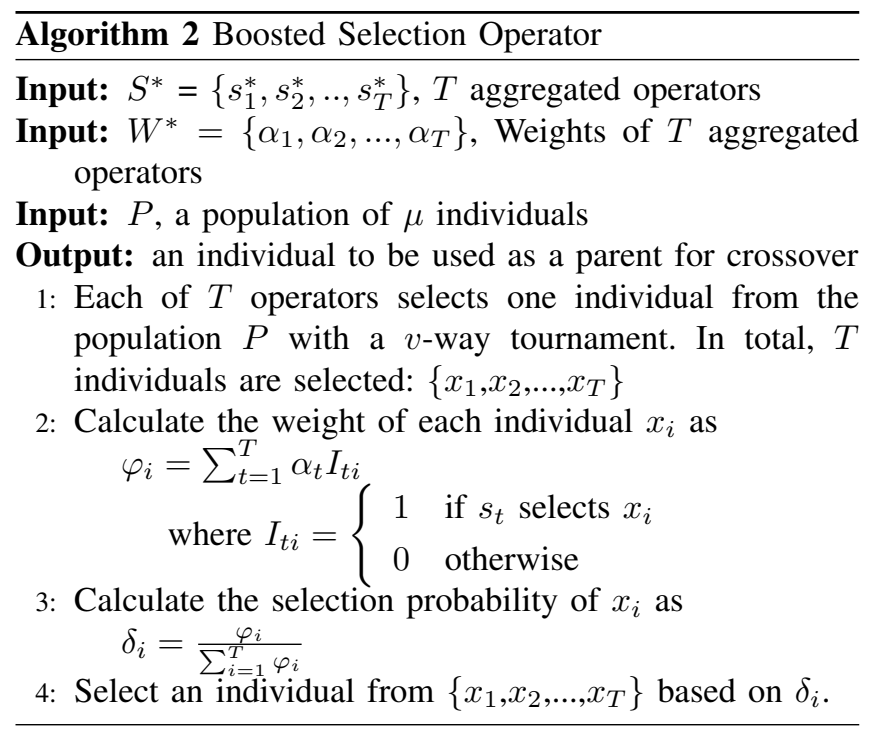

\section{Boosted Parent Selection}

A boosted selection operator is constructed with $T$ operators $S^{*}$ and their weights $W^{*}$, which Algorithm 1 produces. Algorithm 2 shows how a boosted operator works. In a boosted operator, each of $T$ operators first selects one individual from the population $P$ with a $v$-way tournament (Line 1). In a $v$-way tournament, an operator randomly draws two individuals from $P$ and chooses a superior one based on a quality indicator that the operator uses. A weight $\varphi_{i}(1 \leq i \leq T)$ is assigned to each of selected $T$ individuals with a prioritized voting by $T$ operators (Line 2). Priorities are given to individuals based on the weights of operators $\left(\left\{\alpha_{1}, \alpha_{2}, \ldots, \alpha_{T}\right\}\right)$. Finally, a boosted operator chooses one of $T$ individuals as a parent by deriving individual selection probability $\delta_{i}$ from $\varphi_{i}(1 \leq i \leq T)$ (Lines 3 and 4).

\section{EXPERIMENTAL EVALUATION}

This section evaluates the proposed boosting method by integrating a boosted selection operator with a wellknown EMOA, called NSGA-II [15]. The proposed boosting method and NSGA-II are configured as shown in Table II. Experiments were conducted with jMetal [16]. Every experimental result is obtained with 20 independent experiments.

Table II: Algorithmic Configurations
\begin{tabular}{|c|c||c|c|}
\hline Parameter & Value & Parameter & Value \\
\hline \hline$M$ (Algo. 1) & 15 & $v$ (Algo. 2) & $2,3,4,5$ or 6 \\
$T$ (Algo. 1 and 2) & 6 & Max \# of generations & 200 \\
$N$ (Algo. 1) & 5000 & Crossover operator & SBX \\
$\mu$ (Algo. 1 and 2) & 100 & Crossover rate & 0.9 \\
$N_{p}$ (Algo. 1) & 20 & Mutation operator & Polynomial \\
$\theta$ (Algo. 1) & 0.6 & Mutation rate & $1 / \mu$ \\
\hline
\end{tabular}

Table III shows the six indicators that the proposed boosting method chosen from 15 indicators in order to construct a boosted selection opererator. Note that this evaluation study uses $M=15$ and $T=6$ in Algorithms 1 and 2 .
Table III: Aggregated Indicators

\begin{tabular}{|c|c||c|c|}
\hline Indicator & Weight $(\alpha)$ & Indicator & Weight $(\alpha)$ \\
\hline \hline$I_{H D 2}$ & 0.2435 & $I_{W 7}$ & 0.1163 \\
$I_{\epsilon+1}$ & 0.1865 & $I_{W 1}$ & 0.0418 \\
$I_{H y p E}$ & 0.1420 & $I_{W 4}$ & 0.0250 \\
\hline
\end{tabular}

\section{A. Training and Test Problems}

This evaluation study uses ZDT1 as a training problem. ZDT1 is the simplest problem in the ZDT family problems [17]. It has a convex Pareto-optimal front in a two dimensional objective space (Figure 1a).

ZDT2, ZDT3 are ZDT4 are used to evaluate a boosted selection operator that aggregates the indicators shown in Table III. Each of the problems has a two dimensional objective space. ZDT2 is essentially same as ZDT1 in terms of problem design and complexity; however, it has a concave Pareto-optimal front (Figure 1b). ZDT3 and ZDT4 are harder problems than ZDT1. ZDT3 has five discontiguous Paretooptimal fronts (Figure 1c). ZDT4 is a multi-modal problem that has a large number of $\left(20^{9}\right)$ local optima. Its Paretooptimal front is similar to ZDT1's.

DTLZ1 and DTLZ7 [18] are also used as test problems. Both are harder problems than ZDT1. They have three dimensional objective spaces. DTLZ1 has a single Pareto-optimal front and DTLZ7 has 4 discontiguous Paretooptimal fronts (Figures 1d and 1e).

\section{B. Evaluation Metrics}

This paper uses two evaluation metrics: hypervolume ratio (HVR) and inverted generational distance (IGD). HVR is calculated as the ratio of the hypervolume $(H \mathrm{~V})$ of nondominated individuals $(D)$ to the hypervolume of Paretooptimal solutions $\left(P^{*}\right)$ [19].

$$
H V R=\frac{H V(D)}{H V\left(P^{*}\right)}
$$

$H V$ measures the union of the volumes that nondominated individuals dominate [13]. Thus, HVR quantifies the optimality and diversity of non-dominated individuals. A higher HVR indicates that non-dominated individuals are closer to the Pareto-optimal front and more diverse in the objective space.

IGD is computed as follows where $d\left(v_{i}, D\right)$ is the minimum distance from a Pareto-optimal solution $v_{i}$ to $D$ [20].

$$
I G D=\sum_{i=1}^{\left|P^{*}\right|} \frac{d\left(v_{i}, D\right)}{\left|P^{*}\right|}
$$

IGD measures the optimality and diversity (more specifically, extent) of non-dominated individuals. A lower IGD indicates that non-dominated individuals are closer to the Pareto-optimal front and their extent is wider.

For both HVR and IGD, $P^{*}$ are taken uniformly from the Pareto-optimal front. $\left|P^{*}\right|=1001,1001,269,1001$, 1001, 10,000 and 676 in ZDT1, ZDT2, ZDT3, ZDT4, ZDT6, DTLZ1 and DTLZ7. This is the default setting in jMetal. 


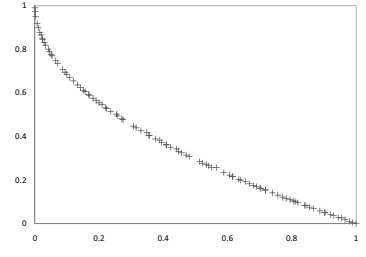

(a) ZDT1

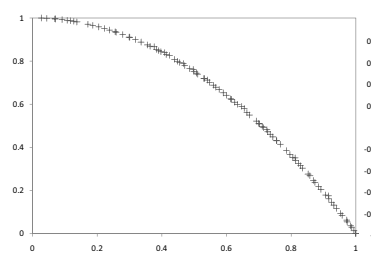

(b) ZDT2

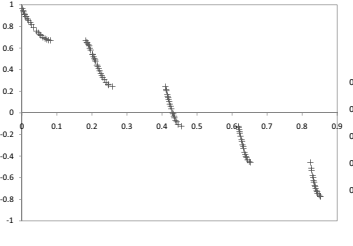

(c) ZDT3

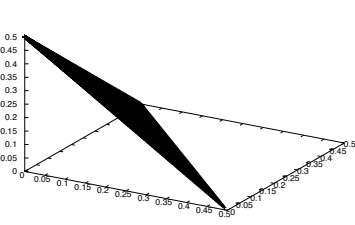

(d) DTLZ1

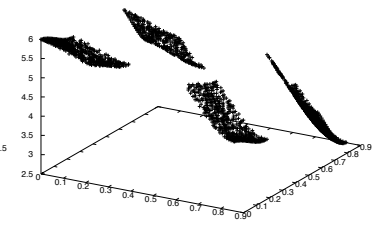

(e) DTLZ7

Figure 1: The Pareto Front Shapes of ZDT1, ZDT2, ZDT3, DTLZ1 and DTLZ7

\section{Optimality and Diversity Analysis}

This section evaluates the optimality and diversity of individuals with HVR and IGD. Table IV shows the average HVR values that seven algorithms yield at the last generation in each problem. $I_{B}$ represents an EMOA that integrates NSGA-II with a boosted selection operator aggregating the six indicators listed in Table III. Each of the other six algorithms represents an EMOA that integrates NSGA-II with a selection operator based on a single indicator. For example, $I_{H D 2}$ represents an EMOA that integrates NSGAII with an $I_{H D 2}$-based selection operator. $v$ indicates the size of a tournament in parent selection. In each problem, 2-way (i.e., binary) to 6-way tournament selections are examined. A bold number indicates the best result among seven algorithms on a per-row basis.

Table IV: Average HVR at the last (the 200th) generation \begin{tabular}{|l|l|l|l|l|l|l|l|}
\hline Problem $\mid v$ & $I_{B}$ & $I_{H D 2}$ & $I_{\varepsilon+1}$ & $I_{H y p E}$ & $I_{W 7}$ & $I_{W 1}$ & $I_{W 4}$ \\
\hline
\end{tabular} \begin{tabular}{|l|l|c|c|c|c|c|c|c|c|}
\hline \hline & 2 & 0.987292 & 0.987013 & 0.987142 & $\mathbf{0 . 9 8 7 9 8 1}$ & 0.987211 & 0.987611 & 0.987187 \\
\cline { 2 - 7 } & 3 & $\mathbf{0 . 9 8 7 9 2}$ & 0.98305 & 0.97806 & 0.987779 & 0.888314 & 0.88346 & 0.891662 \\
\hline
\end{tabular} \begin{tabular}{|l|l|l|l|l|l|l|l|l|l|l|}
\hline 3 & $\mathbf{0 . 9 8 7 9 2}$ & 0.983065 & 0.978066 & 0.987779 & 0.888314 & 0.883464 & 0.891662 \\
\hline
\end{tabular}

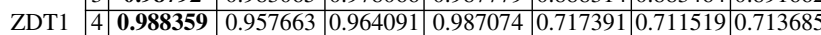
\begin{tabular}{|l|l|l|l|l|l|l|l|l|l|}
\hline $\mathbf{5}$ & $\mathbf{0 . 9 8 8 4 1 4}$ & 0.960003 & 0.955519 & 0.986026 & 0.606751 & 0.57291 & 0.600777 \\
\hline
\end{tabular} \begin{tabular}{|l|l|l|l|l|l|l|l|l|l|}
\hline 6 & $\mathbf{0 . 9 8 8 4 8 4}$ & 0.958924 & 0.950242 & 0.985216 & 0.51941 & 0.482579 & 0.492156 \\
\hline
\end{tabular}

\begin{tabular}{|l|l|l|l|l|l|l|l|l|l|}
\hline 2 & 0.9767 & $\mathbf{0 . 9 7 7 4 4}$ & 0.974778 & 0.976514 & 0.969523 & 0.95584 & 0.961119 \\
\hline
\end{tabular} \begin{tabular}{|l|l|l|l|l|l|l|l|l|l|}
\hline 3 & 0.977363 & $\mathbf{0 . 9 7 7 3 9 3}$ & 0.935134 & 0.977289 & 0.854956 & 0.850348 & 0.854738 \\
\hline
\end{tabular}

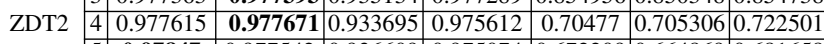

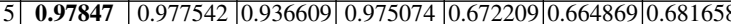
\begin{tabular}{|l|l|l|l|l|l|l|l|l|l|l|}
\hline 6 & 0.976969 & $\mathbf{0 . 9 7 7 4 2 2}$ & 0.924938 & 0.97114 & 0.636568 & 0.619629 & 0.635382 \\
\hline
\end{tabular}

\begin{tabular}{|l|l|l|l|l|l|l|l|l|}
\hline 2 & $\mathbf{0 . 9 9 1 5 9 5}$ & 0.987221 & 0.985653 & 0.989607 & 0.990329 & 0.988545 & 0.988114 \\
\hline
\end{tabular} \begin{tabular}{|l|l|l|l|l|l|l|l|l|l|l|}
\hline 3 & 0.994079 & 0.99411 & 0.9426 & $\mathbf{0 . 9 9 4 9 4 7}$ & 0.851847 & 0.842669 & 0.835347 \\
\hline
\end{tabular}

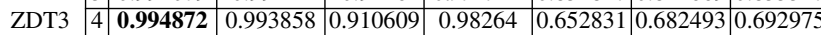
\begin{tabular}{|l|l|l|l|l|l|l|l|l|}
\hline 5 & $\mathbf{0 . 9 9 5 0 6}$ & 0.989828 & 0.8672 & 0.991706 & 0.512317 & 0.546651 & 0.533493 \\
\hline
\end{tabular} \begin{tabular}{|l|l|l|l|l|l|l|l|l|l|}
\hline 6 & $\mathbf{0 . 9 9 5 5 3 5}$ & 0.984116 & 0.832858 & 0.988276 & 0.486224 & 0.476092 & 0.47217 \\
\hline
\end{tabular}

\begin{tabular}{|l|l|l|l|l|l|l|l|l|}
\hline 2 & 0.923535 & 0.881758 & 0.915589 & 0.84696 & 0.973355 & 0.974579 & $\mathbf{0 . 9 7 6 8 7 1}$ \\
\hline
\end{tabular} \begin{tabular}{|l|l|l|l|l|l|l|l|l|l|}
\hline 3 & $\mathbf{0 . 9 6 9 5 5 1}$ & 0.86502 & 0.953591 & 0.903897 & 0.873296 & 0.855642 & 0.869665 \\
\hline
\end{tabular}

\begin{tabular}{ll|l|l|l|l|l|l|l|l|}
\multirow{2}{*}{ ZDT4 } & $\mathbf{0 . 9 7 9 5 8 7}$ & $\mathbf{0 . 9 7 9 8 5 0 5 7}$ & 0.950269 & 0.872678 & 0.656291 & 0.767591 & 0.609153 \\
\cline { 2 - 7 }
\end{tabular} \begin{tabular}{|l|l|l|l|l|l|l|l|l|}
\hline 5 & $\mathbf{0 . 9 7 9 6 0 2}$ & 0.894803 & 0.941216 & 0.917018 & 0.559693 & 0.586559 & 0.60671 \\
\hline
\end{tabular} \begin{tabular}{|l|l|l|l|l|l|l|l|l|l|}
\hline 6 & $\mathbf{0 . 9 7 9 9 8 4}$ & 0.893172 & 0.94369 & 0.92175 & 0.572723 & 0.483191 & 0.481425 \\
\hline
\end{tabular}

\begin{tabular}{|l|l|l|l|l|l|l|l|l|}
2 & 0.963187 & 0.968643 & 0.8065 & $\mathbf{0 . 9 7 3 1 1 7}$ & 0.919929 & 0.92741 & 0.891426 \\
\hline
\end{tabular} \begin{tabular}{|l|l|l|l|l|l|l|l|l|l|l|}
\hline 3 & 0.946998 & $\mathbf{0 . 9 6 3 6 4 4}$ & 0.868354 & 0.958693 & 0.340036 & 0.333922 & 0.373305 \\
\hline
\end{tabular}

\begin{tabular}{|l|l|l|l|l|l|l|l|l|l|l|}
\hline DTLZ1 & 4 & 0.964603 & $\mathbf{0 . 9 7 6 1 9 3}$ & 0.777159 & 0.965573 & 0.23241 & 0.357037 & 0.330733 \\
\cline { 2 - 7 }
\end{tabular} \begin{tabular}{|l|l|l|l|l|l|l|l|l|l|l|}
\hline 5 & $\mathbf{0 . 9 7 6 7 1 6}$ & 0.972869 & 0.760283 & 0.967659 & 0.236244 & 0.375746 & 0.350181 \\
\hline
\end{tabular} \begin{tabular}{|l|l|l|l|l|l|l|l|l|l|l|}
\hline 6 & $\mathbf{0 . 9}$ & & & & \\
\hline 6 & 030752 & $\mathbf{0 . 9 7 4 2 4 5}$ & 0.752827 & 0.966478 & 0.239547 & 0.370695 & 0.274772 \\
\hline
\end{tabular}

\begin{tabular}{|l|l|l|l|l|l|l|l|}
\hline 2 & 0.972382 & 0.852836 & 0.989412 & 0.904304 & $\mathbf{0 . 9 8 8 3 9 5}$ & 0.943761 & 0.97001 \\
\hline
\end{tabular} \begin{tabular}{|l|l|l|l|l|l|l|l|l|l|l|}
\hline 3 & $\mathbf{0 . 9 9 0 3 4 7}$ & 0.921616 & 0.969646 & 0.968427 & 0.680902 & 0.677735 & 0.716543 \\
\hline
\end{tabular}

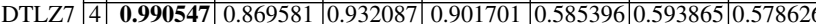

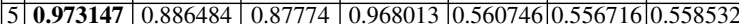
\begin{tabular}{|l|l|l|l|l|l|l|l|l|l|l|}
\hline 6 & $\mathbf{0 . 9 8 9 8 5 8}$ & 0.919655 & 0.805475 & 0.901431 & 0.555464 & 0.555143 & 0.568183 \\
\hline
\end{tabular}

In ZDT1, except in the case of $v=2$, the proposed boosted selection operator $\left(I_{B}\right)$ outperforms the other operators. This is not surprising because $I_{B}$ is constructed with ZDT1 as a training problem. However, a very similar observation can be made in ZDT3, ZDT4 and DTLZ7, which are harder problems than ZDT1. Table IV demonstrates that the proposed boosting process can work with a simple training problem and the boosted selection operator can effectively solve harder problems.

In ZDT2 and DTLZ1, $I_{H D 2}$ performs slightly better than $I_{B}$. (In fact, $I_{B}$ ties $I_{H D 2}$ in ZDT2 if HVR values are truncated to two decimal places.) An important observation is that the performance of $I_{H D 2}$ is inconsistent among different problems. Although $I_{H D 2}$ works well in ZDT2 and DTLZ1, it's performance is marginal in ZDT4 and DTLZ7. In ZDT4, $I_{H D 2}$ never yields the HVR measure of 9.0 or higher. Other indicators exhibit similar inconsistencies. For example, $I_{\epsilon+1}$ performs well in ZDT1 but poorly in DTLZ1. (It never yields the HVR measure of 0.87 or higher in DTLZ1.)

In contrast, $I_{B}$ 's performance is much more consistent among different problems. Its worst HVR is 0.92 in ZDT4 while $I_{H D 2}$ 's worst is $0.85, I_{\epsilon+1}$ 's is $0.75, I_{H y p E}$ 's is $0.84, I_{W 7}$ 's is $0.23, I_{W 7}$ 's is 0.33 , and $I_{W 4}$ 's is 0.27 . This shows that $I_{B}$ allows different indicator-based operators to complement with each other well. In summary, Table IV demonstrates that the proposed $I_{B}$ performs better than, or equally to, existing indicator-based selection operators in HVR (i.e., in optimality and diversity) in all test problems except DTLZ1 and $I_{B}$ is more robust and stable than existing operators under different characteristics in different problems.

Table V shows the average IGD values that seven algorithms yield at the last generation. Similar to the observations for Table IV, $I_{B}$ outperforms existing indicatorbased selection operators in IGD (i.e., in optimality and diversity/extent) in all test problems except DTLZ1 and $I_{B}$ is more robust and stable than existing operators. In DTLZ1, $I_{H D 2}$ performs better than $I_{B}$; however, $I_{H D 2}$ 's performance is inconsistent among problems. For example, it yields marginal IGD measures in DTLZ4 and DTLZ7.

\section{Convergence Velocity Analysis}

This section evaluates the convergence velocity of seven different algorithms with HVR and IGD. Tables VI to XI illustrate convergence velocity with HVR in test problems. Each of these tables shows the number of generations that each algorithm requires to achieve a given HVR value. 
Table V: Average IGD at the last (the 200th) generation \begin{tabular}{|l|l|l|l|l|l|l|l|}
\hline Problem $v$ & $I_{B}$ & $I_{H D 2}$ & $I_{\varepsilon+1}$ & $I_{H y p E}$ & $I_{W 7}$ & $I_{W 1}$ & $I_{W 4}$ \\
\hline
\end{tabular}

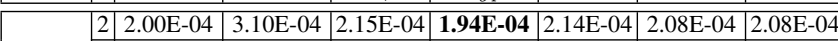
\begin{tabular}{|l|l|l|l|l|l|l|l|l|}
\hline 3 & $1.95 E-04$ & $6.81 \mathrm{E}-04$ & $5.63 \mathrm{E}-04$ & $2.09 \mathrm{E}-04$ & 0.001911 & 0.00203 & 0.001863 \\
\hline
\end{tabular} \begin{tabular}{lllll|l|l|l|l|l|l|l} 
ZDT1 & 4 & 1.91E-04 & 0.002553 & $9.59 \mathrm{E}-04$ & $2.28 \mathrm{E}-04$ & 0.004471 & 0.004839 & 0.00467 \\
\hline
\end{tabular} \begin{tabular}{|l|l|l|l|l|l|l|l|l|l|}
\hline 5 & $1.95 E-04$ & 0.002339 & 0.001163 & $2.49 \mathrm{E}-04$ & 0.006489 & 0.007051 & 0.006703 \\
\hline
\end{tabular} \begin{tabular}{|l|l|l|l|l|l|l|l|l|l|}
\hline 6 & $1.93 E-04$ & 0.002267 & 0.001354 & $2.75 \mathrm{E}-04$ & 0.008201 & 0.009134 & 0.008946 \\
\hline
\end{tabular}

\begin{tabular}{|l|l|l|l|l|l|l|l|}
2 & $1.95 E-04$ & $1.96 \mathrm{E}-04$ & $2.07 \mathrm{E}-04$ & $2.01 \mathrm{E}-04$ & $6.52 \mathrm{E}-04$ & $9.52 \mathrm{E}-04$ & $9.13 \mathrm{E}-04$ \\
\hline
\end{tabular} \begin{tabular}{|l|l|l|l|l|l|l|l|l|}
\hline 3 & $1.95 E-04$ & $2.07 \mathrm{E}-04$ & $7.60 \mathrm{E}-04$ & $2.08 \mathrm{E}-04$ & 0.003351 & 0.003897 & 0.003302 \\
\hline
\end{tabular}

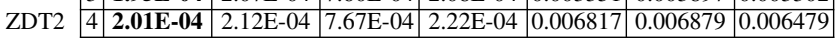
\begin{tabular}{|l|l|l|l|l|l|l|l|l|}
\hline 5 & $\mathbf{1 . 9 7 E}-04$ & $2.12 \mathrm{E}-04$ & $7.21 \mathrm{E}-04$ & $2.34 \mathrm{E}-04$ & 0.007963 & 0.008258 & 0.008299 \\
\hline
\end{tabular} \begin{tabular}{|l|l|l|l|l|l|l|l|l|l|}
\hline 6 & 2.13E-04 & $2.18 \mathrm{E}-04$ & $8.35 \mathrm{E}-04$ & $2.78 \mathrm{E}-04$ & 0.009151 & 0.009998 & 0.009383 \\
\hline
\end{tabular}

\begin{tabular}{|l|l|l|l|l|l|l|l|l|}
\hline 2 & 0.001471 & 0.002558 & $8.68 \mathrm{E}-04$ & $7.41 \mathrm{E}-04$ & $6.73 \mathrm{E}-04$ & $\mathbf{6 . 5 6 E}-04$ & $6.73 \mathrm{E}-04$ \\
\hline
\end{tabular} \begin{tabular}{|l|l|l|l|l|l|l|l|l|}
\hline 3 & $\mathbf{2 . 7 1 E - 0 4}$ & 0.001465 & 0.00303 & $7.42 \mathrm{E}-04$ & 0.007659 & 0.00798 & 0.008523 \\
\hline
\end{tabular}

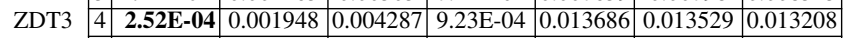
\begin{tabular}{|l|l|l|l|l|l|l|l|}
\hline 5 & $\mathbf{4 . 9 9 E}-04$ & 0.002412 & 0.005524 & $7.21 \mathrm{E}-04$ & 0.020962 & 0.018295 & 0.019788 \\
\hline
\end{tabular} \begin{tabular}{|l|l|l|l|l|l|l|l|l|}
\hline 6 & $\mathbf{2 . 7 0 E}-04$ & 0.003155 & 0.005795 & $7.06 \mathrm{E}-04$ & 0.02299 & 0.023307 & 0.023221 \\
\hline
\end{tabular} \begin{tabular}{|l|l|l|l|l|l|l|l|l|}
\hline 2 & 0.003657 & 0.006448 & 0.004214 & 0.007809 & $3.71 \mathrm{E}-04$ & $4.32 \mathrm{E}-04$ & 3.19E-04 \\
\hline
\end{tabular} \begin{tabular}{|l|l|l|l|l|l|l|l|l|}
\hline 3 & $\mathbf{0 . 0 0 1 2 6 6}$ & 0.007305 & 0.002271 & 0.00443 & 0.001969 & 0.002261 & 0.002179 \\
\hline
\end{tabular}

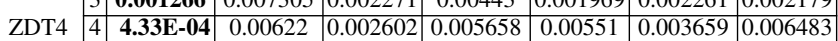
\begin{tabular}{|l|l|l|l|l|l|l|l|l|}
\hline 5 & $\mathbf{2 . 7 6 E - 0 4}$ & 0.006165 & 0.002784 & 0.003276 & 0.007168 & 0.006785 & 0.006833 \\
\hline
\end{tabular} \begin{tabular}{|l|l|l|l|l|l|l|l|l|}
\hline 6 & $2.77 E-04$ & 0.006066 & 0.00255 & 0.003292 & 0.007127 & 0.009118 & 0.00909 \\
\hline
\end{tabular}

\begin{tabular}{|l|l|l|l|l|l|l|l|l|}
2 & $9.63 \mathrm{E}-04$ & $8.13 \mathrm{E}-04$ & 0.007901 & $\mathbf{6 . 9 8 E}-04$ & 0.002678 & 0.002587 & 0.004219 \\
\hline
\end{tabular} \begin{tabular}{|l|l|l|l|l|l|l|l|l|l|}
\hline 3 & 0.001389 & 9.82E-04 & 0.005007 & 0.001125 & 0.040721 & 0.042157 & 0.038842 \\
\hline
\end{tabular}

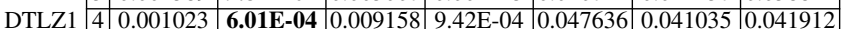
\begin{tabular}{|l|l|l|l|l|l|l|l|l|}
\hline 5 & $\mathbf{5 . 9 0 E}-04$ & $6.77 \mathrm{E}-04$ & 0.008897 & $8.68 \mathrm{E}-04$ & 0.049915 & 0.040208 & 0.040462 \\
\hline
\end{tabular} \begin{tabular}{|l|l|l|l|l|l|l|l|l|l|}
\hline 6 & 0.002744 & $\mathbf{6 . 4 8 E}-04$ & 0.008947 & $9.04 \mathrm{E}-04$ & 0.051819 & 0.039794 & 0.048099 \\
\hline
\end{tabular}

\begin{tabular}{|l|l|l|l|l|l|l|l|l|}
\hline & 0.001423 & 0.009841 & 2.25E-04 & 0.00625 & $2.60 \mathrm{E}-04$ & 0.001198 & $5.60 \mathrm{E}-04$ \\
\hline
\end{tabular} \begin{tabular}{|l|l|l|l|l|l|l|l|l|}
\hline 3 & $\mathbf{2 . 2 3 E}-04$ & 0.005041 & 0.001589 & 0.001739 & 0.006721 & 0.007264 & 0.006671 \\
\hline
\end{tabular}

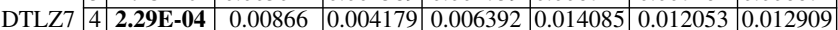
\begin{tabular}{|l|l|l|l|l|l|l|l|l|l|l|}
\hline 5 & $\mathbf{0 . 0 0 1 4 4 6}$ & 0.007512 & 0.007841 & 0.001743 & 0.017194 & 0.017268 & 0.016872 \\
\hline
\end{tabular} \begin{tabular}{|l|l|l|l|l|l|l|l|l|}
\hline 6 & $\mathbf{2 . 5 7 E - 0 4}$ & 0.005104 & 0.012635 & 0.006398 & 0.017714 & 0.018067 & 0.017263 \\
\hline
\end{tabular}

In each problem, 2-way (i.e., binary) to 6-way tournament selections are examined. A bold number indicates the best result among seven algorithms on a per-row basis. For example, $I_{B}$ requires 114 generations to achieve the HVR value of 0.9 with a three-way tournament in ZDT2 (Table VII). Its convergence velocity is the fastest among seven algorithms. A number in parentheses indicates the ratio of convergence velocity between $I_{B}$ and another algorithm (i.e., how faster or slower an algorithm's convergence is against $I_{B}$ ). In Table VII, $I_{H D 2}$ 's convergence is $17 \%$ slower than $I_{B}$ in the case of three-way tournament selection. The character " $x$ " indicates that an algorithm cannot achieve a given HVR value by the last generation.

Tables VI to XI show that $I_{B}$ 's convergence velocity is faster than the others' in ZDT2, ZDT3, ZDT4 and DTLZ7. It is not the best but fairly acceptable in ZDT1 and DTLZ1. The weighted hypervolume indicators $\left(I_{W 7}\right.$, $I_{W 1}$ and $\left.I_{W 4}\right)$ possess greater convergence velocity in many problems to achieve the HVR value of 0.5 . However, they often encounter premature convergence and fail to achieve higher HVR values when $v \geq 3$. $I_{H y p E}$ and $I_{H D 2}$ yield the greatest convergence velocity in ZDT1 and DTLZ1, respectively. However, their convergence velocities are not consistent among different problems. $I_{H y p E}$ 's convergence velocity is marginal in other problems than ZDT1. $I_{H D 2}$ 's is marginal in other problems than DTLZ1.

In contrast, $I_{B}$ never encounters premature convergence. (It never fails to achieve the HVR value of 0.9.) Its convergence velocity is more consistent among different problems.
It is more robust and stable than exiting operators under different characteristics in different problems by allowing them to complement with each other.

Tables XII to XVII show convergence velocity with IGD in ZDT1, ZDT2, ZDT3, ZDT4, DTLZ1 and DTLZ7. Similar to the observations in Tables VI to XI, $I_{B}$ avoids premature convergence and its convergence velocity is greater than, or equal to, the others' in many problems (all problems except DTLZ1). $I_{B}$ 's convergence velocity is more consistent than the others' among different problems; it is more robust and stable than the others.

Table VI: HVR in ZDT1

\begin{tabular}{|c|c|c|c|c|c|c|c|c|}
\hline$v$ & HVR & $I_{B}$ & $I_{H D 2}$ & $I_{\varepsilon+1}$ & $I_{H y p E}$ & $I_{W 7}$ & $I_{W 1}$ & $I_{W 4}$ \\
\hline \hline \multirow{4}{*}{2} & 0.5 & 37 & $37(1.0)$ & $40(1.08)$ & $\mathbf{3 6}(\mathbf{0 . 9 7})$ & $37(1.0)$ & $\mathbf{3 6}(\mathbf{0 . 9 7})$ & $37(1.0)$ \\
\cline { 2 - 10 } & 0.75 & 55 & $56(1.02)$ & $58(1.05)$ & $\mathbf{5 2 ( 0 . 9 5 )}$ & $55(1.0)$ & $54(0.98)$ & $55(1.0)$ \\
\cline { 2 - 10 } & 0.9 & 75 & $79(1.05)$ & $81(1.08)$ & $\mathbf{7 3 ( 0 . 9 7 )}$ & $77(1.03)$ & $76(1.01)$ & $77(1.03)$ \\
\hline \hline \multirow{3}{*}{3} & 0.5 & $\mathbf{3 4}$ & $36(1.06)$ & $40(1.18)$ & $33(0.97)$ & $38(1.12)$ & $36(1.06)$ & $37(1.09)$ \\
\cline { 2 - 9 } & 0.75 & 51 & $53(1.04)$ & $58(1.14)$ & $\mathbf{4 8 ( 0 . 9 4 )}$ & $62(1.22)$ & $61(1.2)$ & $61(1.2)$ \\
\cline { 2 - 9 } & 0.9 & 70 & $74(1.06)$ & $87(1.24)$ & $\mathbf{6 7 ( 0 . 9 6 )}$ & $\mathrm{x}$ & $\mathrm{x}$ & $\mathrm{x}$ \\
\hline \hline \multirow{4}{*}{4} & 0.5 & $\mathbf{3 3}$ & $\mathbf{3 3 ( 1 . 0 )}$ & $46(1.39)$ & $34(1.03)$ & $41(1.24)$ & $41(1.24)$ & $42(1.27)$ \\
\cline { 2 - 9 } & 0.75 & $\mathbf{4 9}$ & $50(1.02)$ & $64(1.31)$ & $\mathbf{4 9}(\mathbf{1 . 0})$ & $\mathrm{x}$ & $\mathrm{x}$ & $\mathrm{x}$ \\
\cline { 2 - 9 } & 0.9 & $\mathbf{6 7}$ & $79(1.18)$ & $93(1.39)$ & $69(1.03)$ & $\mathrm{x}$ & $\mathrm{x}$ & $\mathrm{x}$ \\
\hline \hline \multirow{4}{*}{5} & 0.5 & $\mathbf{3 2}$ & $35(1.09)$ & $46(1.44)$ & $32(1.0)$ & $47(1.47)$ & $55(1.72)$ & $48(1.5)$ \\
\cline { 2 - 9 } & 0.75 & 48 & $51(1.06)$ & $64(1.33)$ & $\mathbf{4 7 ( 0 . 9 8 )}$ & $\mathrm{x}$ & $\mathrm{x}$ & $\mathrm{x}$ \\
\cline { 2 - 9 } & 0.9 & 67 & $77(1.15)$ & $96(1.43)$ & $\mathbf{6 4 ( 0 . 9 6 )}$ & $\mathrm{x}$ & $\mathrm{x}$ & $\mathrm{x}$ \\
\hline \hline \multirow{2}{*}{6} & 0.5 & 34 & $33(0.97)$ & $45(1.32)$ & $\mathbf{3 1 ( 0 . 9 1 )}$ & $78(2.29)$ & $\mathrm{x}$ & $\mathrm{x}$ \\
\cline { 2 - 8 } & 0.75 & 49 & $49(1.0)$ & $66(1.35)$ & $\mathbf{4 6}(\mathbf{0 . 9 4})$ & $\mathrm{x}$ & $\mathrm{x}$ & $\mathrm{x}$ \\
\cline { 2 - 8 } & 0.9 & 68 & $78(1.15)$ & $93(1.37)$ & $\mathbf{6 3 ( 0 . 9 3 )}$ & $\mathrm{x}$ & $\mathrm{x}$ & $\mathrm{x}$ \\
\hline
\end{tabular}

Table VII: HVR in ZDT2

\begin{tabular}{|c|c|c|c|c|c|c|c|c|}
\hline$v$ & HVR & $I_{B}$ & $I_{H D 2}$ & $I_{\varepsilon+1}$ & $I_{H y p E}$ & $I_{W 7}$ & $I_{W 1}$ & $I_{W 4}$ \\
\hline \multirow{3}{*}{2} & 0.5 & 103 & $116(1.13)$ & $88(0.85)$ & $110(1.07)$ & $62(0.6)$ & $61(0.59)$ & $64(0.62)$ \\
\hline & 0.75 & 123 & $135(1.1)$ & $114(0.93)$ & $126(1.02)$ & $79(0.64)$ & $82(0.67)$ & $85(0.69)$ \\
\hline & 0.9 & 144 & $158(1.1)$ & $134(0.93)$ & $144(1.0)$ & $110(0.76)$ & $120(0.83)$ & $119(0.83)$ \\
\hline \multirow{3}{*}{3} & 0.5 & 83 & $99(1.19)$ & $91(1.1)$ & $92(1.11)$ & $55(0.66)$ & $57(0.69)$ & $57(0.69)$ \\
\hline & 0.75 & 99 & $117(1.18)$ & $111(1.12)$ & $106(1.07)$ & $82(0.83)$ & $84(0.85)$ & $84(0.85)$ \\
\hline & 0.9 & 114 & $133(1.17)$ & 134(1.18) & $119(1.04)$ & $\mathrm{x}$ & $\mathrm{x}$ & $\mathrm{x}$ \\
\hline \multirow{3}{*}{4} & 0.5 & 76 & $97(1.28)$ & $100(1.32)$ & $96(1.26)$ & $59(0.78)$ & $59(0.78)$ & $56(0.74)$ \\
\hline & 0.75 & 90 & $109(1.21)$ & $125(1.39)$ & $105(1.17)$ & $\mathrm{X}$ & $\mathrm{x}$ & $\mathrm{x}$ \\
\hline & 0.9 & 108 & $119(1.1)$ & $143(1.32)$ & $122(1.13)$ & $\mathrm{x}$ & $\mathrm{X}$ & $\mathrm{X}$ \\
\hline \multirow{3}{*}{5} & 0.5 & 80 & 94(1.18) & $98(1.23)$ & 94(1.18) & $59(0.74)$ & $60(0.75)$ & 59(0.74) \\
\hline & 0.75 & 95 & $106(1.12)$ & $128(1.35)$ & $109(1.15)$ & $\mathrm{x}$ & $\mathrm{x}$ & $\mathrm{X}$ \\
\hline & 0.9 & 109 & 121(1.11) & $163(1.5)$ & $128(1.17)$ & $\mathrm{x}$ & $\mathrm{x}$ & $\mathrm{x}$ \\
\hline \multirow{3}{*}{6} & 0.5 & 73 & $91(1.25)$ & $118(1.62)$ & $91(1.25)$ & $61(0.84)$ & $65(0.89)$ & $66(0.9)$ \\
\hline & 0.75 & 87 & $105(1.21)$ & $133(1.53)$ & $110(1.26)$ & $\mathrm{x}$ & $\mathrm{x}$ & $\mathrm{x}$ \\
\hline & 0.9 & 102 & $116(1.14)$ & 151(1.48) & $148(1.45)$ & $\mathrm{x}$ & $\mathrm{x}$ & $\mathrm{x}$ \\
\hline
\end{tabular}

Table VIII: HVR in ZDT3

\begin{tabular}{|c|c|c|c|c|c|c|c|c|}
\hline$v$ & HVR & $I_{B}$ & $I_{H D 2}$ & $I_{\varepsilon+1}$ & $I_{H y p E}$ & $I_{W 7}$ & $I_{W 1}$ & $I_{W 4}$ \\
\hline \hline \multirow{2}{*}{2} & 0.5 & 103 & $116(1.13)$ & $88(0.85)$ & $110(1.07)$ & $62(0.6)$ & $\mathbf{6 1 ( 0 . 5 9 )}$ & $64(0.62)$ \\
\cline { 2 - 9 } & 0.75 & 123 & $135(1.1)$ & $114(0.93)$ & $126(1.02)$ & $79(0.64)$ & $\mathbf{8 2 ( 0 . 6 7 )}$ & $85(0.69)$ \\
\cline { 2 - 9 } & 0.9 & 144 & $158(1.1)$ & $134(0.93)$ & $144(1.0)$ & $\mathbf{1 1 0 ( 0 . 7 6 )}$ & $120(0.83)$ & $119(0.83)$ \\
\hline \hline \multirow{2}{*}{3} & 0.5 & 83 & $99(1.19)$ & $91(1.1)$ & $92(1.11)$ & $\mathbf{5 5 ( 0 . 6 6 )}$ & $57(0.69)$ & $57(0.69)$ \\
\cline { 2 - 9 } & 0.75 & 99 & $117(1.18)$ & $111(1.12)$ & $106(1.07)$ & $\mathbf{8 2 ( 0 . 8 3 )}$ & $84(0.85)$ & $84(0.85)$ \\
\cline { 2 - 9 } & 0.9 & $\mathbf{1 1 4}$ & $133(1.17)$ & $134(1.18)$ & $119(1.04)$ & $\mathrm{x}$ & $\mathrm{x}$ & $\mathrm{x}$ \\
\hline \hline \multirow{4}{*}{4} & 0.5 & 76 & $97(1.28)$ & $100(1.32)$ & $96(1.26)$ & $59(0.78)$ & $59(0.78)$ & $\mathbf{5 6 ( 0 . 7 4 )}$ \\
\cline { 2 - 8 } & 0.75 & $\mathbf{9 0}$ & $109(1.21)$ & $125(1.39)$ & $105(1.17)$ & $\mathrm{x}$ & $\mathrm{x}$ & $\mathrm{x}$ \\
\cline { 2 - 8 } & 0.9 & $\mathbf{1 0 8}$ & $119(1.1)$ & $143(1.32)$ & $122(1.13)$ & $\mathrm{x}$ & $\mathrm{x}$ & $\mathrm{x}$ \\
\hline \hline \multirow{2}{*}{5} & 0.5 & 80 & $94(1.18)$ & $98(1.23)$ & $94(1.18)$ & $\mathbf{5 9 ( 0 . 7 4 )}$ & $60(0.75)$ & $\mathbf{5 9 ( 0 . 7 4 )}$ \\
\cline { 2 - 8 } & 0.75 & $\mathbf{9 5}$ & $106(1.12)$ & $128(1.35)$ & $109(1.15)$ & $\mathrm{x}$ & $\mathrm{x}$ & $\mathrm{x}$ \\
\cline { 2 - 8 } & 0.9 & $\mathbf{1 0 9}$ & $121(1.11)$ & $163(1.5)$ & $128(1.17)$ & $\mathrm{x}$ & $\mathrm{x}$ & $\mathrm{x}$ \\
\hline \hline \multirow{2}{*}{6} & 0.5 & 73 & $91(1.25)$ & $118(1.62)$ & $91(1.25)$ & $\mathbf{6 1 ( 0 . 8 4 )}$ & $65(0.89)$ & $66(0.9)$ \\
\cline { 2 - 8 } & 0.75 & $\mathbf{8 7}$ & $105(1.21)$ & $133(1.53)$ & $110(1.26)$ & $\mathrm{x}$ & $\mathrm{x}$ & $\mathrm{x}$ \\
\cline { 2 - 8 } & 0.9 & $\mathbf{1 0 2}$ & $116(1.14)$ & $151(1.48)$ & $148(1.45)$ & $\mathrm{x}$ & $\mathrm{x}$ & $\mathrm{x}$ \\
\hline
\end{tabular}


Table IX: HVR in ZDT4

\begin{tabular}{|c|c|c|c|c|c|c|c|c|}
\hline$v$ & HVR & $I_{B}$ & $I_{H D 2}$ & $I_{\varepsilon+1}$ & $I_{H y p E}$ & $I_{W 7}$ & $I_{W 1}$ & $I_{W 4}$ \\
\hline \hline \multirow{3}{*}{2} & 0.5 & 121 & $129(1.07)$ & $132(1.09)$ & $136(1.12)$ & $98(0.81)$ & $\mathbf{9 5}(\mathbf{0 . 7 9})$ & $\mathbf{9 5 ( 0 . 7 9 )}$ \\
\cline { 2 - 10 } & 0.75 & 148 & $152(1.03)$ & $158(1.07)$ & $177(1.2)$ & $119(0.8)$ & $\mathbf{1 1 3 ( 0 . 7 6 )}$ & $114(0.77)$ \\
\cline { 2 - 10 } & 0.9 & 191 & $210(1.1)$ & $193(1.01)$ & $222(1.16)$ & $144(0.75)$ & $137(0.72)$ & $\mathbf{1 3 5 ( 0 . 7 1 )}$ \\
\hline \hline \multirow{3}{*}{3} & 0.5 & 106 & $114(1.08)$ & $111(1.05)$ & $118(1.11)$ & $83(0.78)$ & $81(0.76)$ & $\mathbf{8 0 ( 0 . 7 5 )}$ \\
\cline { 2 - 10 } & 0.75 & 129 & $142(1.1)$ & $146(1.13)$ & $148(1.15)$ & $107(0.83)$ & $\mathbf{1 0 4 ( 0 . 8 1 )}$ & $109(0.84)$ \\
\cline { 2 - 9 } & 0.9 & $\mathbf{1 5 8}$ & $238(1.51)$ & $178(1.13)$ & $198(1.25)$ & $\mathrm{x}$ & $\mathrm{x}$ & $\mathrm{x}$ \\
\hline \hline \multirow{4}{*}{4} & 0.5 & 94 & $99(1.05)$ & $108(1.15)$ & $107(1.14)$ & $84(0.89)$ & $\mathbf{7 1 ( 0 . 7 6 )}$ & $94(1.0)$ \\
\cline { 2 - 9 } & 0.75 & $\mathbf{1 1 5}$ & $136(1.18)$ & $138(1.2)$ & $153(1.33)$ & $\mathrm{x}$ & $141(1.23)$ & $\mathrm{x}$ \\
\cline { 2 - 9 } & 0.9 & $\mathbf{1 4 1}$ & $235(1.67)$ & $175(1.24)$ & $225(1.6)$ & $\mathrm{x}$ & $\mathrm{x}$ & $\mathrm{x}$ \\
\hline \hline \multirow{3}{*}{5} & 0.5 & 87 & $96(1.1)$ & $108(1.24)$ & $103(1.18)$ & $92(1.06)$ & $79(0.91)$ & $\mathbf{7 5 ( 0 . 8 6 )}$ \\
\cline { 2 - 9 } & 0.75 & $\mathbf{1 0 8}$ & $131(1.21)$ & $141(1.31)$ & $130(1.2)$ & $\mathrm{x}$ & $\mathrm{x}$ & $\mathrm{x}$ \\
\cline { 2 - 9 } & 0.9 & $\mathbf{1 3 5}$ & $217(1.61)$ & $177(1.31)$ & $170(1.26)$ & $\mathrm{x}$ & $\mathrm{x}$ & $\mathrm{x}$ \\
\hline \hline \multirow{3}{*}{6} & 0.5 & 84 & $101(1.2)$ & $100(1.19)$ & $99(1.18)$ & $\mathbf{7 7 ( 0 . 9 2 )}$ & $\mathrm{x}$ & $\mathrm{x}$ \\
\cline { 2 - 9 } & 0.75 & $\mathbf{9 9}$ & $131(1.32)$ & $137(1.38)$ & $136(1.37)$ & $\mathrm{x}$ & $\mathrm{x}$ & $\mathrm{x}$ \\
\cline { 2 - 8 } & 0.9 & $\mathbf{1 2 9}$ & $211(1.64)$ & $184(1.43)$ & $190(1.47)$ & $\mathrm{x}$ & $\mathrm{x}$ & $\mathrm{x}$ \\
\hline
\end{tabular}

Table X: HVR in DTLZ1

\begin{tabular}{|c|c|c|c|c|c|c|c|c|}
\hline$v$ & HVR & $I_{B}$ & $I_{H D 2}$ & $I_{\varepsilon+1}$ & $I_{H y p E}$ & $I_{W 7}$ & $I_{W 1}$ & $I_{W 4}$ \\
\hline \multirow{3}{*}{2} & 0.5 & 129 & $126(0.98)$ & $132(1.02)$ & $110(0.85)$ & $157(1.22)$ & $142(1.1)$ & $155(1.2)$ \\
\hline & 0.75 & 153 & $150(0.98)$ & $169(1.1)$ & $128(0.84)$ & $175(1.14)$ & $163(1.07)$ & $\overline{178(1.16)}$ \\
\hline & 0.9 & 175 & $176(1.01)$ & $224(1.28)$ & 157(0.9) & 194(1.11) & $187(1.07)$ & 204(1.17) \\
\hline \multirow{3}{*}{3} & 0.5 & 122 & $117(0.96)$ & $127(1.04)$ & 111(0.91) & $\mathrm{x}$ & $\mathrm{x}$ & $245(2.01)$ \\
\hline & 0.75 & 139 & 138(0.99) & $178(1.28)$ & $140(1.01)$ & $\mathrm{x}$ & $\mathrm{x}$ & $\mathrm{x}$ \\
\hline & 0.9 & 165 & $180(1.09)$ & $218(1.32)$ & 172(1.04) & $\mathrm{X}$ & $\mathrm{x}$ & $\mathrm{X}$ \\
\hline \multirow{3}{*}{4} & 0.5 & 115 & $105(0.91)$ & $141(1.23)$ & $113(0.98)$ & $\mathrm{x}$ & $\mathrm{x}$ & $\mathrm{x}$ \\
\hline & 0.75 & 142 & $133(0.94)$ & $183(1.29)$ & $135(0.95)$ & $\mathrm{x}$ & $\mathrm{x}$ & $\mathrm{x}$ \\
\hline & 0.9 & 184 & $154(0.84)$ & $\mathrm{X}$ & $162(0.88)$ & $\mathrm{X}$ & $\mathrm{x}$ & $\mathrm{x}$ \\
\hline \multirow{3}{*}{5} & 0.5 & 114 & $100(0.88)$ & $148(1.3)$ & $104(0.91)$ & $\mathrm{x}$ & $\mathrm{x}$ & $\mathrm{x}$ \\
\hline & 0.75 & 144 & 121(0.84) & $195(1.35)$ & $129(0.9)$ & $\mathrm{x}$ & $\mathrm{X}$ & $\mathrm{x}$ \\
\hline & 0.9 & 158 & $132(0.84)$ & $\mathrm{x}$ & $159(1.01)$ & $\mathrm{x}$ & $\mathrm{x}$ & $\mathrm{x}$ \\
\hline \multirow{3}{*}{6} & 0.5 & 119 & $96(0.81)$ & 124(1.04) & $103(0.87)$ & $\mathrm{x}$ & $\mathrm{x}$ & $\mathrm{x}$ \\
\hline & 0.75 & 138 & $118(0.86)$ & 197(1.43) & $126(0.91)$ & $\mathrm{x}$ & $\mathrm{x}$ & $\mathrm{x}$ \\
\hline & 0.9 & 164 & $142(0.87)$ & $\mathrm{x}$ & $136(0.83)$ & $\mathrm{x}$ & $\mathrm{x}$ & $\mathrm{x}$ \\
\hline
\end{tabular}

\section{CONCLUSIONS}

This paper proposes and evaluates a novel method that leverages a boosting algorithm to obtain an aggregated selection operator from various existing indicator-based selection operators. Experimental results show that a boosted selection operator outperforms exiting ones in optimality, diversity and convergence velocity. The proposed boosting process can work with a simple training problem, and the boosted operator can effectively solve harder problems. The boosted operator also exhibits robustness against different character-

Table XI: HVR in DTLZ7

\begin{tabular}{|c|c|c|c|c|c|c|c|c|}
\hline$v$ & $\mathrm{HVR}$ & $I_{B}$ & $I_{H D 2}$ & $I_{\varepsilon+1}$ & $I_{H y p E}$ & $I_{W 7}$ & $I_{W 1}$ & $I_{W 4}$ \\
\hline \hline \multirow{3}{*}{2} & 0.5 & 49 & $52(1.06)$ & $52(1.06)$ & $49(1.0)$ & $\mathbf{4 8}(\mathbf{0 . 9 8})$ & $52(1.06)$ & $49(1.0)$ \\
\cline { 2 - 10 } & 0.75 & $\mathbf{6 1}$ & $71(1.16)$ & $64(1.05)$ & $64(1.05)$ & $66(1.08)$ & $71(1.16)$ & $66(1.08)$ \\
\cline { 2 - 10 } & 0.9 & $\mathbf{8 3}$ & $\mathrm{x}$ & $84(1.01)$ & $152(1.83)$ & $96(1.16)$ & $130(1.57)$ & $104(1.25)$ \\
\hline \hline \multirow{3}{*}{3} & 0.5 & 44 & $43(0.98)$ & $50(1.14)$ & $\mathbf{4 2 ( 0 . 9 5 )}$ & $57(1.3)$ & $53(1.2)$ & $52(1.18)$ \\
\cline { 2 - 9 } & 0.75 & 55 & $55(1.0)$ & $66(1.2)$ & $\mathbf{5 4}(\mathbf{0 . 9 8})$ & $\mathrm{x}$ & $\mathrm{x}$ & $\mathrm{x}$ \\
\cline { 2 - 9 } & 0.9 & $\mathbf{7 1}$ & $91(1.28)$ & $93(1.31)$ & $75(1.06)$ & $\mathrm{x}$ & $\mathrm{x}$ & $\mathrm{x}$ \\
\hline \hline \multirow{4}{*}{4} & 0.5 & 42 & $43(1.02)$ & $50(1.19)$ & $\mathbf{4 0 ( 0 . 9 5 )}$ & $60(1.43)$ & $59(1.4)$ & $64(1.52)$ \\
\cline { 2 - 9 } & 0.75 & $\mathbf{5 2}$ & $57(1.1)$ & $69(1.33)$ & $54(1.04)$ & $\mathrm{x}$ & $\mathrm{x}$ & $\mathrm{x}$ \\
\cline { 2 - 9 } & 0.9 & $\mathbf{6 8}$ & $\mathrm{x}$ & $118(1.74)$ & $179(2.63)$ & $\mathrm{x}$ & $\mathrm{x}$ & $\mathrm{x}$ \\
\hline \hline \multirow{3}{*}{5} & 0.5 & 40 & $\mathbf{3 8 ( 0 . 9 5 )}$ & $51(1.27)$ & $38(0.95)$ & $70(1.75)$ & $73(1.83)$ & $67(1.68)$ \\
\cline { 2 - 9 } & 0.75 & 51 & $52(1.02)$ & $76(1.49)$ & $\mathbf{4 8 ( 0 . 9 4 )}$ & $\mathrm{x}$ & $\mathrm{x}$ & $\mathrm{x}$ \\
\cline { 2 - 9 } & 0.9 & $\mathbf{6 8}$ & $\mathrm{x}$ & $\mathrm{x}$ & $69(1.01)$ & $\mathrm{x}$ & $\mathrm{x}$ & $\mathrm{x}$ \\
\hline \hline \multirow{2}{*}{6} & 0.5 & 39 & $\mathbf{3 8}(\mathbf{0 . 9 7})$ & $52(1.33)$ & $39(1.0)$ & $74(1.9)$ & $73(1.87)$ & $66(1.69)$ \\
\cline { 2 - 9 } & 0.75 & $\mathbf{4 9}$ & $51(1.04)$ & $91(1.86)$ & $54(1.1)$ & $\mathrm{x}$ & $\mathrm{x}$ & $\mathrm{x}$ \\
\cline { 2 - 8 } & 0.9 & $\mathbf{6 4}$ & $82(1.28)$ & $\mathrm{x}$ & $174(2.72)$ & $\mathrm{x}$ & $\mathrm{x}$ & $\mathrm{x}$ \\
\hline
\end{tabular}

Table XII: IGD in ZDT1

\begin{tabular}{|c|c|c|c|c|c|c|c|c|}
\hline$v$ & IGD & $I_{B}$ & $I_{H D 2}$ & $I_{\varepsilon+1}$ & $I_{\text {Hyp }}$ & $I_{W 7}$ & $I_{W 1}$ & $I_{W 4}$ \\
\hline \hline \multirow{4}{*}{1} & 0.01 & 31 & $36(1.16)$ & $32(1.03)$ & $31(1.0)$ & $\mathbf{3 0}(\mathbf{0 . 9 7})$ & $\mathbf{3 0 ( 0 . 9 7 )}$ & $31(1.0)$ \\
\cline { 2 - 9 } & 0.005 & 48 & $59(1.23)$ & $49(1.02)$ & $\mathbf{4 6}(\mathbf{0 . 9 6})$ & $47(0.98)$ & $46(0.96)$ & $47(0.98)$ \\
\cline { 2 - 9 } & 0.001 & 84 & $126(1.5)$ & $96(1.14)$ & $\mathbf{8 2 ( 0 . 9 8 )}$ & $85(1.01)$ & $82(0.98)$ & $84(1.0)$ \\
\hline \hline \multirow{3}{*}{3} & 0.01 & $\mathbf{2 9}$ & $35(1.21)$ & $31(1.07)$ & $29(1.0)$ & $30(1.03)$ & $\mathbf{2 9 ( 1 . 0 )}$ & $\mathbf{2 9 ( 1 . 0 )}$ \\
\cline { 2 - 9 } & 0.005 & $\mathbf{4 4}$ & $59(1.34)$ & $49(1.11)$ & $\mathbf{4 4 ( 1 . 0 )}$ & $49(1.11)$ & $46(1.05)$ & $47(1.07)$ \\
\cline { 2 - 9 } & 0.001 & $\mathbf{7 8}$ & $138(1.77)$ & $138(1.77)$ & $\mathbf{7 8 ( 1 . 0 )}$ & $\mathrm{x}$ & $\mathrm{x}$ & $\mathrm{x}$ \\
\hline \hline \multirow{4}{*}{4} & 0.01 & $\mathbf{2 8}$ & $33(1.18)$ & $36(1.29)$ & $31(1.11)$ & $30(1.07)$ & $30(1.07)$ & $31(1.11)$ \\
\cline { 2 - 9 } & 0.005 & $\mathbf{4 3}$ & $67(1.56)$ & $56(1.3)$ & $47(1.09)$ & $65(1.51)$ & $66(1.53)$ & $70(1.63)$ \\
\cline { 2 - 9 } & 0.001 & $\mathbf{7 4}$ & $\mathrm{x}$ & $186(2.51)$ & $87(1.18)$ & $\mathrm{x}$ & $\mathrm{x}$ & $\mathrm{x}$ \\
\hline \hline \multirow{3}{*}{5} & 0.01 & $\mathbf{2 7}$ & $37(1.37)$ & $35(1.3)$ & $28(1.04)$ & $32(1.19)$ & $36(1.33)$ & $32(1.19)$ \\
\cline { 2 - 9 } & 0.005 & $\mathbf{4 1}$ & $68(1.66)$ & $56(1.37)$ & $43(1.05)$ & $\mathrm{x}$ & $\mathrm{x}$ & $\mathrm{x}$ \\
\cline { 2 - 9 } & 0.001 & $\mathbf{7 4}$ & $\mathrm{x}$ & $\mathrm{x}$ & $76(1.03)$ & $\mathrm{x}$ & $\mathrm{x}$ & $\mathrm{x}$ \\
\hline \hline \multirow{2}{*}{6} & 0.01 & 28 & $33(1.18)$ & $35(1.25)$ & $\mathbf{2 8 ( 1 . 0 )}$ & $36(1.29)$ & $40(1.43)$ & $44(1.57)$ \\
\cline { 2 - 9 } & 0.005 & $\mathbf{4 3}$ & $62(1.44)$ & $57(1.33)$ & $\mathbf{4 3 ( 1 . 0 )}$ & $\mathrm{x}$ & $\mathrm{x}$ & $\mathrm{x}$ \\
\cline { 2 - 8 } & 0.001 & $\mathbf{7 6}$ & $\mathrm{x}$ & $\mathrm{x}$ & $78(1.03)$ & $\mathrm{x}$ & $\mathrm{x}$ & $\mathrm{x}$ \\
\hline
\end{tabular}

Table XIII: IGD in ZDT2

\begin{tabular}{|l|l|l|l|l|l|l|l|l|}
\hline$v$ & IGD & $I_{B}$ & $I_{H D 2}$ & $I_{\varepsilon+1}$ & $I_{H y p E}$ & $I_{W 7}$ & $I_{W 1}$ & $I_{W 4}$ \\
\hline & 0.01 & $y_{0}$ & $I$ & &
\end{tabular} \begin{tabular}{|c|c|c|c|c|c|c|c|c|c|}
\hline & 0.01 & 103 & $117(1.14)$ & $82(0.8)$ & $110(1.07)$ & $49(0.48)$ & $\mathbf{4 8 ( 0 . 4 7 )}$ & $51(0.5)$ \\
\hline
\end{tabular} \begin{tabular}{|l|l|l|l|l|l|l|l|l|}
2 & 0.005 & 124 & $137(1.1)$ & $108(0.87)$ & $127(1.02)$ & $\mathbf{6 5}(\mathbf{0 . 5 2})$ & $\mathbf{6 5 ( 0 . 5 2 )}$ & $69(0.56)$ \\
\hline
\end{tabular} \begin{tabular}{|l|l|l|l|l|l|l|l|}
\hline 0.001 & 158 & $168(1.06)$ & $143(0.91)$ & $157(0.99)$ & $\mathbf{1 3 0 ( 0 . 8 2 )}$ & $196(1.24)$ & $174(1.1)$ \\
\hline
\end{tabular} \begin{tabular}{|c|c|c|c|c|c|c|c|c|}
\hline & 0.01 & 80 & $98(1.23)$ & $86(1.08)$ & $91(1.14)$ & $\mathbf{4 3 ( 0 . 5 4 )}$ & $44(0.55)$ & $45(0.56)$ \\
\hline
\end{tabular}

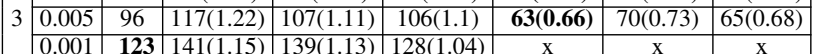

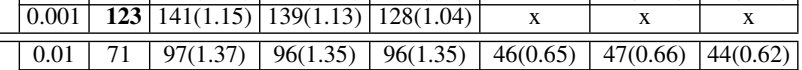
\begin{tabular}{|c|c|c|c|c|c|c|c|c|}
4 & 0.005 & $\mathbf{8 7}$ & $109(1.25)$ & $124(1.43)$ & $105(1.21)$ & $\mathrm{x}$ & $\mathrm{x}$ & $\mathrm{x}$ \\
\hline & 0.001 & $\mathbf{1 1 2}$ & $125(1.12)$ & $147(1.31)$ & $130(1.16)$ & $\mathrm{x}$ & $\mathrm{x}$ & $\mathrm{x}$ \\
\hline
\end{tabular}

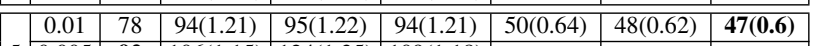
\begin{tabular}{|c|c|c|c|c|c|c|c|c|}
5 & 5.005 & $\mathbf{9 2}$ & $106(1.15)$ & $124(1.35)$ & $109(1.18)$ & $\mathrm{x}$ & $\mathrm{x}$ & $\mathrm{x}$ \\
\cline { 2 - 8 } & 0.001 & $\mathbf{1 1 4}$ & $127(1.11)$ & $178(1.56)$ & $135(1.18)$ & $\mathrm{x}$ & $\mathrm{x}$ & $\mathrm{x}$ \\
\hline
\end{tabular} \begin{tabular}{|c|c|c|c|c|c|c|c|c|}
\hline & 0.01 & 70 & $92(1.31)$ & $116(1.66)$ & $90(1.29)$ & $\mathbf{5 1 ( 0 . 7 3 )}$ & $57(0.81)$ & $54(0.77)$ \\
\hline
\end{tabular} \begin{tabular}{|l|r|r|r|r|r|r|r|r|}
6 & 0.005 & $\mathbf{8 4}$ & $105(1.25)$ & $132(1.57)$ & $109(1.3)$ & $\mathrm{x}$ & $\mathrm{x}$ & $\mathrm{x}$ \\
\hline & 0.001 & $\mathbf{1 0 6}$ & $123(1.16)$ & $157(1.48)$ & $161(1.52)$ & $\mathrm{x}$ & $\mathrm{x}$ & $\mathrm{x}$ \\
\hline
\end{tabular}

istics in different problems and yields stable performance to solve them.

Several future extensions are planned for the proposed boosting method. First, the notion of boosted indicator-based selection will be studied in environmental selection as well as parent selection. (Environmental selection chooses a set of individuals used in the next generation from the union of the current population and its offspring.) Second, the notion of boosted indicator-based selection will be evaluated in other problems than ZDT and DTLZ problems.

\section{REFERENCES}

[1] N. Srinivas and K. Deb, "Multiobjective function optimization using nondominated sorting genetic algorithms," Evol. Computat., vol. 2, no. 3, 1995.

[2] C. C. Coello, "Evolutionary multi-objective optimization: Some current research trends and topics that remain to be explored," Front. Computat. Sci. China, vol. 3, no. 1, 2009.

[3] T. Wagner, N. Beume, and B. Naujoks, "Pareto-, aggregation-, and indicator-based methods in many-objective optimization," in Proc. Int'l Conf. Evol. Multi-criterion Optimization, 2007.

[4] E. Zitzler, D. Brockho, and L. Thiele, "The Hypervolume Indicator Revisited: On the Design of Pareto-compliant Indicators Via Weighted Integration," in Proc. of Int'l Conference on Evolutionary Multi-Criterion Optimization, 2007. 
Table XIV: IGD in ZDT3

\begin{tabular}{|c|c|c|c|c|c|c|c|c|}
\hline$v$ & IGD & $I_{B}$ & $I_{H D 2}$ & $I_{\varepsilon+1}$ & $I_{H y p}$ & $I_{W 7}$ & $I_{W 1}$ & $I_{W 4}$ \\
\hline \hline \multirow{3}{*}{2} & 0.01 & 40 & $41(1.02)$ & $45(1.13)$ & $\mathbf{3 7}(\mathbf{0 . 9 3})$ & $42(1.05)$ & $42(1.05)$ & $41(1.02)$ \\
\cline { 2 - 10 } & 0.005 & 60 & $65(1.08)$ & $69(1.15)$ & $\mathbf{5 6}(\mathbf{0 . 9 3})$ & $63(1.05)$ & $63(1.05)$ & $63(1.05)$ \\
\cline { 2 - 10 } & 0.001 & $\mathrm{x}$ & $\mathrm{x}$ & 185 & $\mathbf{1 1 5}$ & 161 & 156 & 169 \\
\hline \hline \multirow{3}{*}{3} & 0.01 & 38 & $\mathbf{3 5}(\mathbf{0 . 9 2})$ & $55(1.45)$ & $36(0.95)$ & $57(1.5)$ & $60(1.58)$ & $63(1.66)$ \\
\cline { 2 - 10 } & 0.005 & $\mathbf{5 6}$ & $\mathbf{5 6}(\mathbf{1 . 0})$ & $121(2.16)$ & $57(1.02)$ & $\mathrm{x}$ & $\mathrm{x}$ & $\mathrm{x}$ \\
\cline { 2 - 9 } & 0.001 & $\mathbf{1 0 5}$ & $\mathrm{x}$ & $\mathrm{x}$ & $179(1.7)$ & $\mathrm{x}$ & $\mathrm{x}$ & $\mathrm{x}$ \\
\hline \hline \multirow{3}{*}{4} & 0.01 & 35 & $\mathbf{3 3 ( 0 . 9 4 )}$ & $66(1.89)$ & $\mathbf{3 3 ( 0 . 9 4 )}$ & $\mathrm{x}$ & $\mathrm{x}$ & $\mathrm{x}$ \\
\cline { 2 - 9 } & 0.005 & $\mathbf{5 2}$ & $\mathbf{5 2 ( 1 . 0 )}$ & $163(3.13)$ & $53(1.02)$ & $\mathrm{x}$ & $\mathrm{x}$ & $\mathrm{x}$ \\
\cline { 2 - 9 } & 0.001 & $\mathbf{1 0 1}$ & $\mathrm{x}$ & $\mathrm{x}$ & $198(1.96)$ & $\mathrm{x}$ & $\mathrm{x}$ & $\mathrm{x}$ \\
\hline \hline \multirow{3}{*}{5} & 0.01 & $\mathbf{3 5}$ & $\mathbf{3 5}(\mathbf{1 . 0})$ & $82(2.34)$ & $34(0.97)$ & $\mathrm{x}$ & $\mathrm{x}$ & $\mathrm{x}$ \\
\cline { 2 - 9 } & 0.005 & 52 & $58(1.12)$ & $235(4.52)$ & $\mathbf{5 0 ( 0 . 9 6 )}$ & $\mathrm{x}$ & $\mathrm{x}$ & $\mathrm{x}$ \\
\cline { 2 - 9 } & 0.001 & $\mathbf{1 2 5}$ & $\mathrm{x}$ & $\mathrm{x}$ & $159(1.27)$ & $\mathrm{x}$ & $\mathrm{x}$ & $\mathrm{x}$ \\
\hline \hline \multirow{3}{*}{6} & 0.01 & $\mathbf{3 5}$ & $\mathbf{3 5}(\mathbf{1 . 0})$ & $76(2.17)$ & $33(0.94)$ & $\mathrm{x}$ & $\mathrm{x}$ & $\mathrm{x}$ \\
\cline { 2 - 9 } & 0.005 & $\mathbf{5 1}$ & $69(1.35)$ & $\mathrm{x}$ & $52(1.02)$ & $\mathrm{x}$ & $\mathrm{x}$ & $\mathrm{x}$ \\
\cline { 2 - 9 } & 0.001 & $\mathbf{9 9}$ & $\mathrm{x}$ & $\mathrm{x}$ & $150(1.52)$ & $\mathrm{x}$ & $\mathrm{x}$ & $\mathrm{x}$ \\
\hline
\end{tabular}

Table XV: IGD in ZDT4

\begin{tabular}{|c|c|c|c|c|c|c|c|c|}
\hline$v$ & IGD & $I_{B}$ & $I_{H D 2}$ & $I_{\varepsilon+1}$ & $I_{H y p E}$ & $I_{W 7}$ & $I_{W 1}$ & $I_{W 4}$ \\
\hline \multirow{3}{*}{2} & 0.01 & 148 & 162(1.09) & 162(1.09) & 184(1.24) & $104(0.7)$ & $98(0.66)$ & $96(0.65)$ \\
\hline & 0.005 & 187 & $231(1.24)$ & 193(1.03) & $225(1.2)$ & $120(0.64)$ & $119(0.64)$ & $114(0.61)$ \\
\hline & 0.001 & 243 & $\mathrm{x}$ & $241(0.99)$ & $\mathrm{x}$ & $165(0.68)$ & 171(0.7) & $155(0.64)$ \\
\hline \multirow{3}{*}{3} & 0.01 & 129 & 151(1.17) & $148(1.15)$ & 153(1.19) & $83(0.64)$ & $79(0.61)$ & $76(0.59)$ \\
\hline & 0.005 & 158 & $\mathrm{x}$ & $176(1.11)$ & $196(1.24)$ & $100(0.63)$ & $95(0.6)$ & $97(0.61)$ \\
\hline & 0.001 & 203 & $\mathrm{x}$ & $221(1.09)$ & $\mathrm{x}$ & $\mathrm{x}$ & $\mathrm{x}$ & $\mathrm{x}$ \\
\hline \multirow{3}{*}{4} & 0.01 & 111 & $144(1.3)$ & $137(1.23)$ & $155(1.4)$ & $71(0.64)$ & $68(0.61)$ & $76(0.68)$ \\
\hline & 0.005 & 135 & $\mathrm{x}$ & 172(1.27) & $213(1.58)$ & $\mathrm{x}$ & $90(0.67)$ & $\mathrm{x}$ \\
\hline & 0.001 & 173 & $\mathrm{x}$ & $221(1.28)$ & $\mathrm{x}$ & $\mathrm{x}$ & $\mathrm{x}$ & $\mathrm{x}$ \\
\hline \multirow{3}{*}{5} & 0.01 & 104 & 134(1.29) & $146(1.4)$ & 134(1.29) & $68(0.65)$ & $65(0.63)$ & $65(0.63)$ \\
\hline & 0.005 & 124 & $\mathrm{x}$ & $175(1.41)$ & $160(1.29)$ & $\mathrm{x}$ & $\mathrm{x}$ & $\mathrm{x}$ \\
\hline & 0.001 & 161 & $\mathrm{x}$ & $224(1.39)$ & $\mathrm{x}$ & $\mathrm{x}$ & $\mathrm{x}$ & $\mathrm{x}$ \\
\hline \multirow{3}{*}{6} & 0.01 & 95 & $136(1.43)$ & 143(1.51) & $138(1.45)$ & $66(0.69)$ & $73(0.77)$ & $76(0.8)$ \\
\hline & 0.005 & 114 & $\mathrm{x}$ & $182(1.6)$ & 181(1.59) & $\mathrm{x}$ & $\mathrm{x}$ & $\mathrm{x}$ \\
\hline & 0.001 & 159 & $\mathrm{x}$ & $229(1.44)$ & $\mathrm{x}$ & $\mathrm{x}$ & $\mathrm{x}$ & $\mathrm{x}$ \\
\hline
\end{tabular}

[5] J. Bader and E. Zitzler, "HypE: An algorithm for fast hypervolume-based many-objective optimization," Evol. Computat., vol. 19, no. 1, 2011.

[6] E. Zitzler and S. Kuenzli., "Indicator-based selection in multiobjective search," in Proc. of Int'l Conference on Parallel Problem Solving from Nature, 2004.

[7] P. Boonma and J. Suzuki, "Prospect indicator based evolutionary multiobjective optimization algorithm," in Proc. IEEE Congress on Evolutionary Computation, 2011.

[8] B. Liu, M. B., and A. H.A., "Improving genetic classifiers with a boosting algorithm," in Proc. IEEE Congress on Evolutionary Computation, 2003.

[9] B. Liu, B. McKay, and H. A. Abbass, "Feature selection combining genetic algorithm and adaboost classifiers," in Proc. Int'l Conference on Pattern Recognition, 2008.

[10] I. Yalabik and T.-V. Fatos, "A pattern classification approach for boosting with genetic algorithms," in Proc. Int'l Symposium on Computer and Information Sciences, 2007.

[11] G. Paris, D. Robilliard, and C. Fonlupt, "Applying boosting techniques to genetic programming," in Proc. European Conference on Artificial Evolution, 2002.

[12] L. V. Souza, A. R. T. Pozo, J. C. M. Da Rosa, and C. Neto, "Technique using correlation coefficient to improve time series forecasting accuracy," in Proc. IEEE Congress on Evolutionary Computation, 2007.
Table XVI: IGD in DTLZ1

\begin{tabular}{|c|c|c|c|c|c|c|c|c|}
\hline$v$ & IGD & $I_{B}$ & $I_{H D 2}$ & $I_{\varepsilon+1}$ & $I_{\text {HypE }}$ & $I_{W 7}$ & $I_{W 1}$ & $I_{W 4}$ \\
\hline \multirow{3}{*}{2} & 0.01 & 152 & $146(0.96)$ & 193(1.27) & $123(0.81)$ & 174(1.14) & $162(1.07)$ & $177(1.16)$ \\
\hline & 0.005 & 170 & $175(1.03)$ & $221(1.3)$ & $144(0.85)$ & $185(1.09)$ & $178(1.05)$ & $200(1.18)$ \\
\hline & 0.001 & 196 & $194(0.99)$ & $\mathrm{x}$ & $188(0.96)$ & $\mathrm{x}$ & $\mathrm{x}$ & $\mathrm{X}$ \\
\hline \multirow{3}{*}{3} & 0.01 & 142 & 153(1.08) & $178(1.25)$ & 152(1.07) & $\mathrm{x}$ & $\mathrm{x}$ & $\mathrm{x}$ \\
\hline & 0.005 & 155 & $178(1.15)$ & $202(1.3)$ & $163(1.05)$ & $\mathrm{x}$ & $\mathrm{x}$ & $\mathrm{x}$ \\
\hline & 0.001 & 205 & $200(0.98)$ & $\mathrm{x}$ & $206(1.0)$ & $\mathrm{x}$ & $\mathrm{X}$ & $\mathrm{x}$ \\
\hline \multirow{3}{*}{4} & 0.01 & 142 & 133(0.94) & 177(1.25) & $134(0.94)$ & $\mathrm{x}$ & $\mathrm{X}$ & $\mathrm{x}$ \\
\hline & 0.005 & 182 & $145(0.8)$ & $\mathrm{x}$ & $146(0.8)$ & $\mathrm{x}$ & $\mathrm{x}$ & $\mathrm{x}$ \\
\hline & 0.001 & 201 & $175(0.87)$ & $\mathrm{x}$ & $198(0.99)$ & $\mathrm{x}$ & $\mathrm{x}$ & $\mathrm{x}$ \\
\hline \multirow{3}{*}{5} & 0.01 & 144 & $119(0.83)$ & 184(1.28) & $134(0.93)$ & $\mathrm{x}$ & $\mathrm{x}$ & $\mathrm{x}$ \\
\hline & 0.005 & 151 & $126(0.83)$ & $\mathrm{x}$ & $154(1.02)$ & $\mathrm{x}$ & $\mathrm{x}$ & $\mathrm{x}$ \\
\hline & 0.001 & 177 & $163(0.92)$ & $\mathrm{x}$ & $198(1.12)$ & $\mathrm{X}$ & $\mathrm{x}$ & $\mathrm{x}$ \\
\hline \multirow{3}{*}{6} & 0.01 & 154 & $117(0.76)$ & 176(1.14) & $125(0.81)$ & $\mathrm{x}$ & $\mathrm{x}$ & $\mathrm{x}$ \\
\hline & 0.005 & 167 & $126(0.75)$ & $\mathrm{x}$ & $131(0.78)$ & $\mathrm{x}$ & $\mathrm{x}$ & $\mathrm{x}$ \\
\hline & 0.001 & 207 & $158(0.76)$ & $\mathrm{x}$ & $190(0.92)$ & $\mathrm{x}$ & $\mathrm{x}$ & $\mathrm{x}$ \\
\hline
\end{tabular}

Table XVII: IGD in DTLZ7

\begin{tabular}{|c|c|c|c|c|c|c|c|c|}
\hline$v$ & IGD & $I_{B}$ & $I_{H D 2}$ & $I_{\varepsilon+1}$ & $I_{H y p E}$ & $I_{W 7}$ & $I_{W 1}$ & $I_{W 4}$ \\
\hline & 0.01 & 42 & $103(2.45)$ & $\overline{41(0.98)}$ & $49(1.17)$ & $\overline{40(0.95)}$ & $43(1.02)$ & $\overline{40(0.95)}$ \\
\hline \multirow[t]{2}{*}{ 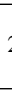 } & 0.005 & 54 & $\mathrm{x}$ & $51(0.94)$ & $\mathrm{x}$ & $52(0.96)$ & $59(1.09)$ & $53(0.98)$ \\
\hline & 0.001 & $\mathrm{x}$ & $\mathrm{x}$ & 81 & $\mathrm{x}$ & 108 & 248 & 124 \\
\hline \multirow{3}{*}{3} & 0.01 & 36 & $40(1.11)$ & $40(1.11)$ & 34(0.94) & $53(1.47)$ & $50(1.39)$ & $52(1.44)$ \\
\hline & 0.005 & 44 & $\mathrm{x}$ & $52(1.18)$ & $45(1.02)$ & $\mathrm{x}$ & $\mathrm{x}$ & $\mathrm{x}$ \\
\hline & 0.001 & 69 & $\mathrm{x}$ & $\mathrm{x}$ & $\mathrm{x}$ & $\mathrm{x}$ & $\mathrm{x}$ & $\mathrm{x}$ \\
\hline \multirow{3}{*}{4} & 0.01 & 34 & $55(1.62)$ & $44(1.29)$ & $40(1.18)$ & $\mathrm{x}$ & $\mathrm{x}$ & $\mathrm{x}$ \\
\hline & 0.005 & 43 & $\mathrm{x}$ & $89(2.07)$ & $\mathrm{X}$ & $\mathrm{x}$ & $\mathrm{x}$ & $\mathrm{x}$ \\
\hline & 0.001 & 67 & $\mathrm{x}$ & $\mathrm{x}$ & $\mathrm{x}$ & $\mathrm{x}$ & $\mathrm{x}$ & $\mathrm{x}$ \\
\hline \multirow{3}{*}{5} & 0.01 & 34 & $42(1.24)$ & $55(1.62)$ & $31(0.91)$ & $\mathrm{x}$ & $\mathrm{x}$ & $\mathrm{x}$ \\
\hline & 0.005 & 45 & $\mathrm{x}$ & $\mathrm{x}$ & $43(0.96)$ & $\mathrm{x}$ & $\mathrm{X}$ & $\mathrm{x}$ \\
\hline & 0.001 & $\mathrm{x}$ & $\mathrm{x}$ & $\mathrm{x}$ & $\mathrm{x}$ & $\mathrm{x}$ & $\mathrm{x}$ & $\mathrm{x}$ \\
\hline \multirow{3}{*}{6} & 0.01 & 33 & $37(1.12)$ & $\mathrm{x}$ & $40(1.21)$ & $\mathrm{x}$ & $\mathrm{x}$ & $\mathrm{x}$ \\
\hline & 0.005 & 40 & $\mathrm{x}$ & $\mathrm{x}$ & $\mathrm{x}$ & $\mathrm{x}$ & $\mathrm{x}$ & $\mathrm{x}$ \\
\hline & 0.001 & 64 & $\mathrm{x}$ & $\mathrm{x}$ & $\mathrm{x}$ & $\mathrm{x}$ & $\mathrm{x}$ & $\mathrm{x}$ \\
\hline
\end{tabular}

[13] E. Zitzler and L. Thiele, "Multiobjective optimization using evolutionary algorithms: A comparative study," in Proc. Int'l Conference on Parallel Problem Solving from Nature, 1998.

[14] Y. Freund and R. E. Schapire, "A decision-theoretic generalization of on-line learning and an application to boosting," Journal of Computer and System Sciences, vol. 55, 1997.

[15] K. Deb, A. Pratap, S. Agarwal, and T. Meyarivan, "A fast and elitist multiobjective genetic algorithm: NSGA-II," IEEE Trans Evol. Computat., vol. 6, no. 2, 2002.

[16] J. Durillo, A. Nebro, and E. Alba, "The jMetal framework for multi-objective optimization: Design and architecture," in Proc. of IEEE Congress on Evolutionary Computation, 2010.

[17] E. Zitzler, K. Deb, and L. Thiele, "Comparison of multiobjective evolutionary algorithms: Empirical results," Evol. Computat., vol. 8, no. 2, 2000.

[18] K. Deb, L. Thiele, M. Laumanns, and E. Zitzler, "Scalable test problems for evolutionary multiobjective optimization," in Evolutionary Multiobjective Optimization, A. Abraham, R. Jain, and R. Goldberg, Eds. Springer, 2005.

[19] D. A. V. Veldhuizen and G. B. Lamont, "Multiobjective evolutionary algorithm test suites," in Proc. ACM Symposium on Applied Computing, 1999.

[20] —, "Multiobjective evolutionary algorithm research: A history and analysis," in Technical Report TR-98-03, Air Force Institute of Technology, 1998. 